\title{
El eslogan político español en la campaña de elecciones generales de 2008
}

\author{
Palma PEÑA JimÉnEZ \\ Universidad Rey Juan Carlos \\ palma.pena@urjc.es \\ Miguel Ángel OrTIZ SoBrino \\ Universidad Complutense de Madrid \\ maortiz@ccinf.ucm.es
}

Recibido: 13/01/2011

Aceptado: 22/06/2011

\section{Resumen}

El eslogan es la frase que sintetiza la estrategia de una campaña electoral: un mensaje breve que muestra los atributos más relevantes de un candidato o de una organización política, que capta la atención y condensa el beneficio prometido. Los partidos, al igual que sucede en el ámbito comercial, presentan siempre en sus respectivas campañas un lema que identifica a la formación y a su líder, un mensaje que se repite en cada acto programado, en cada cartel, en cada valla publicitaria, en cada spot televisivo. Este artículo es un estudio sobre el eslogan político español, con especial atención a las novedades de la última convocatoria de elecciones generales.

Palabras clave: eslogan, logo, partido político, campaña, propaganda.

\section{The spanish political slogan in the campaign for 2008 general elections}

\begin{abstract}
The slogan is a phrase that synthesises the strategy of an electoral campaign: it's a sharp message that shows the most relevant values of a candidate or a political party. It also grasps the audience attention and summarises the promised benefits. Political parties, as commercial enterprises, do always use a motto that identifies the organisation and its leader, a message repeated in every public event, in every sign, in every outdoor, in every television spot. This article studies the Spanish political slogan, with special attention to the innovations of the last call for general elections.
\end{abstract}

Keywords: slogan, logo, political party, campaign, propaganda.

\section{Referencia normalizada}

PEÑA JIMÉNEZ, Palma y ORTIZ SOBRINO, Miguel Ángel (2011): "El eslogan político español en la campaña de elecciones generales de 2008". Estudios sobre el mensaje periodístico, vol. 17, núm. 2, págs.: 549-568. Madrid, Servicio de Publicaciones de la Universidad Complutense.

Sumario: 1. Introducción. 1.1 Fuentes y metodología, 2. El eslogan como componente teórico, 2.1 Definición del eslogan, 2.2 Características del eslogan, 3. El eslogan como herramienta electoral persuasiva, 4. Los componentes de la comunicación en el esloagn político, 4.1 Quién. El emisor, 4.2 El destinatario. Modelos de destinatario en el mensaje político, 4.3 El entorno, el contexto y las circunstancias, 5. El eslogan en la campaña de 2008, 5.1 La campaña del PSOE en 2008, 5.1.1 Trece lemas para una campaña: el caso del PSOE en 2008, 5.2 La campaña del PP en 2008, 5.3 Los otros partidos, 6. Conclusiones, 7. Referencias Bibliográficas.

\section{Introducción}

Las campañas electorales son, por definición, de naturaleza adversarial, y en ellas, los partidos en lid enfatizan los mensajes persuasivos con el fin de ganar las elecciones, objetivo último al que destinarán todos sus recursos.

La comunicación ejercida es diferida, mediatizada y distanciada por los diferentes soportes. Además es aleatoria, en cuanto se dirige a un público que, en principio, no 
la espera. Este es el motivo por el que debe ser interpelado al instante. Se ha de captar, en primera instancia, la atención del destinatario para conseguir comunicar y -sólo así- hacerlo eficazmente.

Este trabajo sobre el eslogan político español se centra en la campaña de elecciones generales de marzo de 2008 -última convocatoria al Parlamento celebrada en nuestro país-, aunque sin olvidar algunas referencias en clave comparativa y diacrónica de eslóganes presentados por los principales partidos y coaliciones en otras fechas.

Nuestro análisis no es diacrónico, pero sí se remite, puntualmente, a muestras de otras convocatorias, con el fin de indicar y subrayar mejor sus peculiaridades, la evolución y los cambios producidos. El objetivo es comprobar la tendencia actual del eslogan político, poniendo de manifiesto -en su caso- la paulatina pérdida de contenido ideológico en los mensajes de las campañas actuales.

La propaganda política, singularmente en tiempo de campaña, pretende persuadir al cuerpo electoral para obtener su favor traducido en voto. Y así, todas las estrategias comunicativas que se plantean en estos períodos se dirigen a tal fin. No en vano, la disputa política, "pese a su repetición continua, despierta siempre el interés de los medios de comunicación, de la opinión pública y de las ciencias sociales" (MAZzolENI, 2010). Es el momento de mayor interacción entre los diferentes actores y cuando las dinámicas comunicativas adquieren mayor actividad, aunque también hay quienes afirman que los regímenes democráticos se encuentran hoy en "campaña permanente" (Blumenthal, 1980). Lo que es evidente es que vivimos una política principalmente mediática y las campañas electorales se centran en el uso de los medios. El objetivo de esta política mediática se centra en un mensaje que consiste en apoyar al candidato y rechazar al adversario (CASTELLS, 2009:275).

El eslogan político se encuentra entre esas herramientas propagandísticas que cobran todo su vigor en campaña electoral, un período que la vigente ley española, reguladora del Régimen Electoral, define como "el conjunto de actividades lícitas llevadas a cabo por los candidatos, partidos, federaciones, coaliciones o agrupaciones, en orden a la captación de sufragios"'. La campaña se muestra así como un tiempo tasado en el que, haciendo uso de distintas "actividades organizativas y comunicativas", los candidatos trabajan en el ánimo de hacer triunfar sus pretensiones, fijando para ello, previamente, un determinado mensaje (TUESTA SolDEVILLA, 2005:119).

En este modelo presente de democracia centrada en los medios (SWANSON, 1995), la propaganda política concentra todos sus esfuerzos en estos períodos de campaña, como vía masiva y preferencial de comunicación con el ciudadano, como escenario también para la proyección del candidato y para la difusión de mensajes suficientemente persuasivos que consigan alcanzar el voto favorable del electorado. En este sentido, la campaña electoral consiste en "un proceso de persuasión intenso, planeado y controlado, que se realiza durante el período precedente a las elecciones, de acuerdo con reglas que restringen sus métodos, tiempo y costos; está dirigido a todos o algunos de los electores registrados en una división electoral y su propósito es influir en su decisión a la hora de emitir el voto" (MARTínez Silva, 1997:3).

\footnotetext{
${ }^{1}$ Artículo 50.2 de la Ley Orgánica 5/1985, de 19 de junio, del Régimen Electoral General.
} 


\subsection{Fuentes y metodología}

El presente estudio tiene tres objetivos fundamentales. En primer lugar definir de manera rigurosa la unidad lingüística que representa el eslogan. En segundo lugar, determinar las características concretas del eslogan político en la actualidad en nuestro país para, finalmente, explicar y concretar el propósito estratégico de estos enunciados. Entendiendo el eslogan como acto comunicativo intencional y de carácter persuasivo, pretendemos constatar los elementos definitorios del proceso de comunicación empleados a tal efecto.

Para conseguir tales fines, se ha partido del análisis riguroso de todos los eslóganes presentados por los partidos y coaliciones que concurrieron a la última campaña de elecciones generales celebrada en nuestro país en marzo de 2008.

Nuestro corpus es completo, ya que analizamos cada uno de los eslóganes presentados en dicha convocatoria -elecciones generales del 9 de marzo de 2008-, comicios que darían lugar a la $9^{\text {a }}$ Legislatura Constitucional. Nos hemos ayudado, a efectos de recopilación, de la observación atenta de dicha campaña, así como de la lectura de diferentes medios durante el período electoral, sin olvidar las manifestaciones que suministran los partidos sobre sus estrategias comunicativas.

Presentamos, a continuación nuestro estudio. En una primera parte abordaremos de manera sistematizada un conjunto de perspectivas orientadas a analizar el eslogan desde un punto de vista teórico, centrado en las principales definiciones y características que presenta esta herramienta. En segundo lugar, acometeremos el análisis de todos los eslóganes presentados por las partidos y coaliciones que concurrieron a la última campaña a elecciones generales, para finalizar con las conclusiones correspondientes.

\section{El eslogan como componente teórico}

La unidad lingüística que, en nuestro caso, representa el eslogan político, va más allá del texto, y se encuadra en el contexto -siempre político- de la campaña electoral. Su objetivo se colma al conseguir que el destinatario del discurso lleve a término una acción que se traduzca en un voto favorable. Esta es la dimensión pragmática de la retórica actual: el arte de la palabra socialmente eficaz y la comunicación social que aspira a persuadir a los ciudadanos mediante el discurso.

El eslogan político es parte central de la propaganda y suele expresar un objetivo, una promesa puntual o una aspiración. Acompaña todas las campañas publicitarias, comerciales y políticas. Es también la fórmula que cierra el anuncio de televisión o el spot político, ejerciendo, en este caso, una función de anclaje del mensaje (PEÑA JiMÉNEZ \& GARCÍA JIMÉNEZ, 2010).

Etimológicamente, la palabra eslogan viene del inglés slogan -que, a su vez, procede de dos palabras gaélicas, sluagh y gairm-, que en la antigua Escocia significaba "grito de guerra de un clan". El término pasó a Inglaterra en el siglo XVI, donde, a finales del XIX, adquiere el significado de "consigna" de un partido político. En el siglo $\mathrm{XX}$, los estadounidenses utilizan esta voz para referirse a la frase breve y atractiva que figuraba en los carteles y en los anuncios de prensa. $Y$ con este nuevo sentido regresa a Europa, coincidiendo con el tiempo de los totalitarismos. De consigna electo- 
ral en Reino Unido a expresión publicitaria en Norteamérica, y después, de nuevo, de la publicidad a la política, y de la política a la publicidad. Hoy está presente en la comunicación institucional, empresarial y política.

El eslogan es una fórmula breve, llamativa, empleada en un contexto político o comercial como expresión reiterada de una idea o de un propósito, con el fin de condensar la principal promesa de una campaña. Debe ser capaz de atraer la atención de sus destinatarios y resultar de fácil recuerdo, para fijar la idea o promesa pretendida.

El eslogan publicitario debe asociarse al producto o a la marca, y a los valores que la acompañan (Ariel es blancura; Duracell es duración); del mismo modo el eslogan político también debe poner en valor su mensaje.

El eslogan político no puede permitirse tantas licencias estilísticas como la campaña comercial, porque su público es más amplio, menos seleccionado, más heterogéneo, y necesita ser entendido claramente por todos. Sí comparte con el comercial el objetivo de crear y afianzar una imagen de marca/candidato que trasmita prestigio y confianza. Aunque, ciertamente -como recuerda MARTín SALGADO (2002: 80)- "el votante suele considerar la credibilidad de los candidatos solo en términos relativos: quién es más creíble". Un eslogan será más evocador en la medida que sea fácil de percibir, de comprender, de retener y de repetir (ReBoul, 1978: 42).

Las organizaciones políticas cuentan con otros escenarios donde reforzar su discurso. Es el caso de los mítines, que permiten argumentar y presentar con mayor extensión el programa del partido, aunque la idea central de la campaña se traslada por medio de los llamados "símbolos compartidos", con pocas palabras y en pocos segundos. No en vano, los electores conocen y recuerdan los eslóganes de los partidos porque son breves, se centran en lo importante y se reciben repetidamente por distintos medios y en los diferentes formatos -vallas publicitarias, prensa, cuña de radio, formato audiovisual-. Sin embargo, tan sólo una minoría leerá los programas o atenderá a discursos extensos.

Junto a las técnicas de marketing y la "modernización/americanización" (SWANSON \& MANCINI, 1996) de la estrategia electoral, la tendencia actual aconseja el uso de discursos breves, centrados en una sola idea, en sintonía plena con las características formales y de efectividad del eslogan o del spot televisivo. En un tiempo en que la prioridad del discurso político no es ideológica ni se centra en los contenidos, el eslogan tiene como objetivo, esencialmente, su efectividad persuasiva y la brevedad de sus discurso. CANEL y SANDERS (2010: 7-48), ponen de manifiesto la profesionalización de la comunicación de los gobiernos, la escasa información que acompaña al discurso político y la prevalencia del elemento persuasivo.

\subsection{Definición del eslogan}

A continuación se presentan algunas definiciones del eslogan que pueden encontrarse en la bibliografía más relevante:

- HAAS (1965) lo define como "aforismo que, actuando por repetición en el conjunto de una campaña publicitaria [...], sirve hoy para designar cualquier fórmula breve, concisa, fácil de retener debido a su brevedad y hábil para impresionar la mente". 
- Reboul (1978: 109) considera el eslogan como "una fórmula concisa y llamativa, fácilmente repetible, polémica y lo más a menudo anónima, destinada a hacer actuar a las masas tanto por su estilo como por el elemento de autojustificación posicional o racional que comporta. Como el poder de incitación del eslogan, excede siempre su sentido explícito, el término es más o menos peyorativo".

- SÁNCHEZ GuZMÁn (1995: 82) entiende el eslogan como el elemento del anuncio más conocido y divulgado. Su uso no se limita sólo al ámbito comercial, sino que pertenece al amplio espectro de la comunicación persuasiva, singularmente al ámbito de la propaganda política y al adoctrinamiento religioso, distintos en cuanto a su finalidad, pero semejantes en cuanto a sus mecanismos de actuación. Según este autor, "más acertada, si cabe, es la expresión inglesa catchword aplicada al eslogan, pues ésta expresa el 'golpetazo' dirigido a la atención del receptor con el fin de atraerle hacia la marca o el producto que es objeto de la promoción. Aunque esta función suele reservarse al titular de su anuncio, el eslogan la cumple cuando se convierte en un resumen de lo afirmado en el titular".

- Por último, GARRIDO LORA (2000: 29-60) define el eslogan como "la expresión lingüística, económica, significativa, brillante, perdurable, exclusiva y eficiente de una estrategia de comunicación empresarial, política e institucional"

Se trata, en definitiva, de una expresión breve, clara, concisa, fácil de repetir y recordar, centrada en la promesa principal. La repetición y la visibilidad constituyen las medidas de su éxito. Es evidente que el eslogan es uno de los elementos más atrae la atención. Su acertada elección es importante porque cuando se trata de comunicación de alta intensidad y con grandes audiencias, el eslogan es una de las herramientas más visibles que refleja la propuesta esencial del partido, posiciona el tono y el estilo de la campaña, además de a su candidato, como nos señalan SANCHís et al (2009: 162).

\subsection{Características del eslogan}

Un eslogan debe ajustarse a una serie de características que se pueden resumir en los siguientes puntos, siguiendo a PeÑa Pérez, (1999: 143-154):

- Sonoro, como el grito de guerra del que procede, porque se concibe para golpear adecuadamente el oído y, después, permanecer en la memoria.

- Corto, como uno de los requisitos para que pueda ser recordado.

- Claro, por cuanto requerir del destinatario un ejercicio de comprensión, llevará al abandono.

- Sencillo, como condición para alcanzar a un auditorio amplio y diverso. Los eslóganes confusos son ineficientes: no cumplen con su papel y no alcanzan sus objetivos.

- Capaz de atraer la atención.

- Debe incluir el nombre del candidato y/o el nombre o el logotipo del partido, en cuanto firma e identificación de su imagen de marca.

- Debe ser optimista. En este sentido, los expertos en comunicación política americanos aseguran que el optimismo es, en sí mismo, persuasivo. Y esa es una de las razones por las que -salvo contadas excepciones- siempre se eligen lemas de carácter positivo. 
- Sencillo, porque el hipérbaton o una sintaxis barroca dificultan la comprensión y el recuerdo.

Se resume, por tanto, en la brevedad que obliga a la condensación, lo que implica elegir los términos apropiados: aquellos verdaderamente capaces de concentrar más contenido.

No debe olvidarse, tampoco, la obsequiosidad y el agasajo que acompañan siempre al discurso político, en general. Se trata de una retórica que venera a la mayoría, no tanto para inspirarla o intentar cambiar las cosas y reformarlas, sino para halagarla, para atraparla en su mensaje, y para que se sienta orgullosa de lo que ya es (MARTín SALGADO, 2002:87). WiLES (1969: 203-204) define, ya en 1969, la expresión populista como "cualquier credo o movimiento basado en la premisa de que la virtud reside en la gente corriente, que son una aplastante mayoría, y en sus tradiciones colectivas".

Ejemplos de eslóganes populistas no faltan a lo largo de las campañas. Jimmy Carter acuñó en 1976 el lema "Un gobierno tan bueno como su gente", y es célebre también el de Michael Dukakis, en la campaña de 1888: "A tu lado"; "América puede" fue uno de los eslóganes de Reagan, lema este último que recuerda inequívocamente el más actual "Yes, we can" de Obama en 2008. Con sentencias de este tipo, los candidatos tratan de agradar al elector, resultar atractivos y simpáticos -en inglés, likeability-, gustar y emocionar en mayor medida que pueda hacerlo el adversario.

El lenguaje publicitario-político tiene una voluntad más persuasiva que informativa, asemejándose al discurso laudatorio. Pretende ganar la adhesión del receptor, sin necesidad de demostrar verdad alguna, porque resulta suficiente la verosimilitud. Convencer al destinatario, en un corto plazo, sobre las ventajas del partido que representa para -en definitiva- conseguir la adhesión, aunque sólo sea momentánea.

\section{El eslogan como herramienta electoral persuasiva}

En contraposición a los regímenes impositivos, las democracias son sistemas eminentemente comunicativos. Las organizaciones políticas precisan de la comunicación persuasiva para conseguir el voto favorable del electorado, siendo ésta la única vía legítima para optar a las tareas de gobierno. Las campañas actuales son definitivamente mediáticas, los discursos ideológicos están en declive, y la adhesión del público se obtiene gracias a mensajes emocionales y afectivos.

En esta circunstancia impera lo que DADER (2008: 234) denomina "sensiocracia", una suerte de "ideología del sentimiento en la que los puntos de vista o valores no se transmiten mediante la articulación de ideas, sino de manifestaciones de los sentidos, y en la que las informaciones del entorno que recibimos no las procesamos en términos de verdad, rigor $\mathrm{u}$ otras categorías intelectivas, sino simplemente en términos de empatía o dispatía sentimental". Y en dicho contexto cobran especial relieve aquellas estrategias comunicativas que permiten transmitir mensajes capaces de generar reacciones pasionales.

La retórica es el arte de la elocuencia mediante el lenguaje, lo que implica que sea eminentemente pragmática, como pragmático también es el lenguaje, cuyo propósito principal es la persuasión. Generalmente lanzamos o emitimos un mensaje para conseguir algo: para modificar una conducta, recabar la atención de alguien, sustituir o ac- 
tivar una idea..., y en el caso del discurso político convencer, “ya del todo, ya tan sólo parcialmente, mediante la información y la persuasión que están contenidas en el proceso de comunicación" (LÓPEZ EIRE, 2000:12).

Algunos filósofos -Kant, singularmente- distinguían entre persuasión y convicción, ligando, de un lado la persuasión con las emociones, con la parte afectiva de la lengua, y conectando, de otro, la convicción con el mundo de las reflexiones.

En el discurso político, muy especialmente, las palabras se expresan con una intencionalidad -por y para algo-, se argumenta con el ánimo de convencer, motivar o persuadir, para influir en la actuación de una tercera persona. Entre los instrumentos principales que permiten colaborar en este sentido, destaca el eslogan político electoral, objeto de este estudio.

El contexto histórico, político y social adquiere en este tipo de mensajes una relevancia notable, ya que las palabras que conforman el discurso político -en puridad, todos los discursos- no pueden separarse en ningún caso de su situación de uso, ni del momento político en que fueron pronunciadas o utilizadas. Sirvan de ejemplo términos como "talante", "cambio", "consenso", "pinza", "centro", "pacto" o "España va bien", que asociaremos inmediatamente -cada una de ellas por separado- a una concreta formación política, a un líder determinado, y a un momento político específico. Palabras y eslóganes que adquieren su propio significado, su exacto y concreto sentido, sólo unidas al contexto al que pertenecen.

Señala SARTORI (2007: 290) que en la paz, la política -por lo menos la política ideológica- es "guerra de palabras" y en esta guerra de términos lo importante es apropiarse para el bando propio de los signos y palabras emotivas y positivas, así como colocar al adversario con las denominaciones contrarias con carga emotiva negativa. Adueñarse de una palabra es apropiarse de la realidad que denota y también de todas sus connotaciones, adueñarse del término, por ejemplo, "progreso" o "progresistas" no solo supone apropiarse de sus connotaciones, sino también de todo el universo semántico que conlleva y que bien vehiculado comporta grandes beneficios. Además, bien jugado entraña -también- poder colocar al adversario político en el polo contrario del término y su campo semántico, en esa dicotomía que suele establecer el discurso político-electoral.

El eslogan político no es, por tanto, sólo lo que presenta, sino lo que es capaz de evocar, lo que implica, las connotaciones que conlleva. Su mayor o menor acierto dependerá de uno de los conceptos fundamentales en la teoría pragmática: la idea de adecuación del enunciado al contexto de emisión, como factor fundamental para el éxito o fracaso. La leyenda "Por el cambio" (PSOE, 1982) triunfó como eslogan en la medida en que fue plena su adecuación al contexto y, podemos ver como se ha convertido con el paso del tiempo en un término tabú, del que todos quieren adueñarse.

Lo importante del lema político no es su grado de adecuación a la realidad - ¿en qué medida es cierto tal o cual mensaje?-, como tampoco resulta de especial interés el nivel de corrección de su estructura gramatical o su sintaxis. Lo único verdaderamente decisivo es el grado de adecuación del mensaje, su nivel de oportunidad y, al fin, comprobar que colabora eficazmente en la consecución del fin propuesto. Las palabras han de pronunciarse en las circunstancias apropiadas porque pueden fracasar en su 
propósito si fallan de un modo u otro las convenciones que las regulan. Esto no significa otra cosa que cuanto más adecuado -adecuación en el sentido de apropiado al contexto socio-político del momento- resulte el eslogan elegido, más efectivo será. Y así, el lema ha de pensarse cuidadosamente para cada campaña, para cada momento, y sopesar bien cuáles son los temas compartidos por la opinión pública. Adelantarse a las circunstancias, con mensajes que no están interiorizados por la opinión pública, tampoco funcionará, como le ocurrió al Partido Popular en el 2008. ${ }^{2}$

\section{Los componentes de la comunicación en el eslogan político}

¿Quién dice qué, a quién y en qué circunstancia?

\subsection{Quién. El emisor}

El emisor es quien produce el mensaje, el partido político en cuestión, que emite intencionalmente una expresión lingüística, el eslogan de campaña, en un contexto dado y en una situación determinada. Se trata de un acto intencional y concreto, mediante el cual el emisor transmite el simbolismo de su organización, su imagen corporativa, intentando, así, fijar una percepción concreta sobre la misma.

El emisor y el destinatario poseen experiencias y conocimientos comunes, que entra directamente en juego en este proceso comunicativo. El emisor, en este caso el partido político, debe tener en cuenta esas experiencias comunes.

El quién emite el mensaje tiene, a estos efectos, una gran importancia porque los ciudadanos poseen creencias previas y suposiciones sobre cada uno de los partidos, y no son igualmente receptivos a los distintos mensajes. Los militantes y afines de una determinada opción política revelan una predisposición positiva inequívoca al mensaje de su partido, en la misma medida que los simpatizantes de formaciones rivales muestran una clara tendencia negativa al mensaje de su adversario. El emisor forma parte, así, del mensaje mismo.

\subsection{EI destinatario. Modelos de destinatario en el mensaje político}

Con el nombre de destinatario se designa a la persona o personas a quienes dirige el emisor su mensaje. El receptor puede ser cualquier sujeto, pero el destinatario es, inequívocamente, aquel a quien, intencionalmente, se dirige el mensaje, la persona para quien se ha construido el discurso. El crédito que la opinión pública concede a los medios de comunicación es primordial, y así "la influencia que tiene el contenido de los medios en los juicios que los ciudadanos se hacen sobre la política y los políticos se estudia bajo la noción de priming (los medios preparan el juicio, es decir, activan asociaciones en la mente del ciudadano, privilegiando así ciertos criterios) y de framing (el enfoque de las cuestiones)" (CANEL \& SANDERS 2010: 19).

\footnotetext{
${ }^{2}$ A tal efecto podríamos indicar uno de los spots que presentó el Partido Popular en las elecciones de marzo de 2008, centrado en el tema de la crisis, pero que no tuvo los efectos esperados, porque la crisis como tema todavía no se encontraba instalada en la opinion pública. El mismo spot visto dos años después adquiere muchas connotaciones que entonces pasaron desapercibidas.
} 
En función de la situación en que se desarrollen las elecciones y la marcha de los sondeos, así como de los conocimientos que a través de estudios demoscópicos tienen los partidos sobre los temas que preocupan a los votantes, los destinatarios del eslogan serán los simpatizantes y los afiliados, los ciudadanos en general, etc.

En ocasiones, la pretensión del mensaje es conservar el voto propio, como ha sido el caso del eslogan "Si tú no vas, ellos vuelven" (PSC, 2008). Pero existe una relación entre los mensajes y sus audiencias que es fundamental en el terreno político, ya que el público es el medio para conseguir los fines -el voto-, que establece una relación directa del gobernante con el gobernado.

En otras ocasiones, el discurso se dirige a la mayoría de ciudadanos, porque se trata de aglutinar y sumar votos, de aunar mayorías para ganar en las urnas, como el eslogan "Por el cambio" (PSOE, 1982).

El destinatario, en cualquiera de los casos, es fundamental en la comunicación persuasiva, es el objetivo mismo del mensaje. Es a quien hay que convencer y su perfil determina el tipo de discurso. Pero, además, si las noticias relacionadas con la política se presentan como infoentretenimiento y con un mensaje que conecte con las emociones e intereses del receptor, se procesan y se recuerdan mejor (CASTELLS, 2009: 276).

Generalmente, los anuncios no se dirigen a públicos generales, sino a grupos específicos, a targets concretos de destinatarios. Siempre existe una estrecha relación entre el mensaje publicitario y su público y sucede lo mismo en el caso del eslogan político, aunque los públicos -en esta ocasión- son más generales y menos específicos, los targets están menos definidos.

Las actitudes políticas del electorado son diversas, no son homogéneas y se pueden agrupar del siguiente modo:

1. Los que tienen interés por la política, pero no están ni firme ni previamente posicionados. Son susceptibles de ser persuadidos.

2. Los posicionados (auto-identificación con derecha o izquierda). Su decisión es previa a la campaña electoral e independiente de ella. Aceptarán cualquier mensaje de su formación. Su posicionamiento previo les hace poco susceptibles de un cambio de filas. Votarán, sí o sí, a favor de una opción. Son el llamado suelo del partido.

3. Los desinteresados. Para este grupo es más adecuado un mensaje menos político y más emotivo. Están indecisos, pero son influenciables. Es en este segmento en el que suelen centrar los partidos su estrategia de cierre de campaña. Para estos, son aceptables los eslóganes del tipo "Yes, we can" y menos aquellos del tipo "Socialismo es libertad" (PSOE, 1977); "Comunismo es libertad; Votar comunista es votar democracia" (PCE, 1977), de las primeras campañas democráticas españolas, con un contenido más ideológico.

Lo que importa de las campañas electorales es persuadir al electorado para que vote una determinada opción política, y así, "mediante la comunicación, se intentará reforzar las convicciones de los partidarios o votantes leales, cristalizar el apoyo latente del 'elector frágil' o votante indeciso con predisposición favorable, transformar en electores frágiles a los votantes indecisos que están predispuestos a votar por otro, seducir a los indecisos a secas -que son potenciales votantes para ser activados por todos- $\mathrm{y}$, si 
fuera posible, convertir a los hostiles u opositores convenciéndolos de que, para esa elección, sería mejor sufragar por el candidato de otro partido. Asimismo, la persuasión puede dirigirse a la motivación del voto" (GARCíA BEAUDOUX, 2005: 29-30).

El eslogan político es un elemento de persuasión que contribuye a fijar la imagen y el mensaje central de la campaña, a reforzar la totalidad, aunque en la decisión del voto influyen múltiples factores. En la decisión del voto influyen el llamado temperamento político, las opiniones circunstanciales, la pertenencia a un grupo social previo, las creencias adquiridas a lo largo de la vida, la percepción del momento político, el grado de confianza hacia partidos y políticos, la circunstancia personal, entre otras razones, es lo que algunos llaman el humor de los electores, con su grado relativo de optimismo o su grado de descontento con el gobierno de turno y las circunstancia que vive en ese momento cada ciudadano. La evaluación del humor va a condicionar el tono de la campaña electoral y fijará el tipo de mensaje. Si el grado de descontento con el gobierno de turno es bajo, el tono de la campaña debe ser también bajo, neutro, mientras que en la situación contraria hay que subir el tono del discurso. Es decir, la situación y el contexto como factores inseparables del mensaje.

La misión del destinatario será recuperar toda la intención comunicativa e informativa que contiene el mensaje. Inferir lo que el emisor de ese mensaje -el partido político- ha querido trasmitir en el breve discurso del eslogan.

\subsection{El entorno, el contexto y las circunstancias}

Ningún texto es interpretable fuera de su correspondiente contexto espacio-temporal, y mucho menos un discurso de carácter político. En cada texto, en cada discurso, en cada acto de habla hay que tener en cuenta el contexto extraverbal, es decir el conjunto de circunstancias que son conocidas por el hablante, es decir, todo aquello que, física o culturalmente rodea el acto de enunciación. La particular circunstancia, histórica, cultural y política de la comunidad concreta en la que se presenta el discurso. Igual que no hablamos igual en diferentes contextos sociales, tampoco decimos los mismo en distintas circunstancias sociales, culturales y políticas.

Cada una de estas situaciones determina el sentido del mensaje. Las campañas actúan en contextos políticos con características previas y, a diferencia de aquellas campañas que -en el ámbito empresarial- se diseñan a largo plazo, la estrategia de comunicación de una campaña política busca resultados inmediatos. Por esta razón, sus creadores deben afinar al máximo sus instrumentos de persuasión.

En el eslogan referido de la campaña socialista de 1982, "Por el cambio", resumía perfectamente la estrategia de sus promotores para aquel momento concreto. Se ofrecía a la sociedad española un "cambio" basado en la modernización y el Estado del bienestar, que suponía, al mismo tiempo, cerrar el círculo de la alternancia, lo que consolidaría definitivamente la democracia española, dando por concluido el período histórico de la Transición. El término "cambio" fue, muy a propósito, una expresión polisémica. De un lado, hacía referencia a una modificación interna: el abandono definitivo del marxismo, la necesidad de abrir el partido y centrarlo para conseguir la mayoría necesaria que le llevaría al poder. El eslogan reflejaba un proyecto de renovación y de relevo generacional: el "cambio" sustituía también al término "revolución". 
Felipe González, el candidato socialista a presidir el Gobierno de España en aquellos comicios, cerraba sus mítines con un mensaje reiterado durante los 25 días de campaña. Ante medio millón de simpatizantes, concentrados en la explanada de la Ciudad Universitaria de Madrid, González sentenció: "Si hay un pasado que fue de ellos, el futuro es nuestro, de nuestra libertad consciente. El futuro es de la mayoría que quiere el cambio. Adelante. Conquistaremos el futuro en paz. Conquistaremos en libertad. Dejemos a nuestros hijos una España mejor, con el esfuerzo solidario de todos. Adelante y a ganar. España y el futuro es nuestro" (FERNÁndeZ \& GARCíA, 1982).

Cuando una formación política es vista con credibilidad por parte de su audiencia potencial y lógica, los resultados en las elecciones pueden acercarse a la victoria final, y esto es lo que consiguió González en la campaña de 1982 (ARCEO VACAS, 1993).

Las Juventudes Socialistas utilizaron para esa campaña el eslogan "Muévete por el cambio. Vota PSOE", donde se observa el apoyo al lema central de los socialistas, a cuyo "cambio" añadieron el imperativo "muévete", relacionando la política con la "movida" imperante en aquel momento socio-cultural, intentando así "movilizar" -

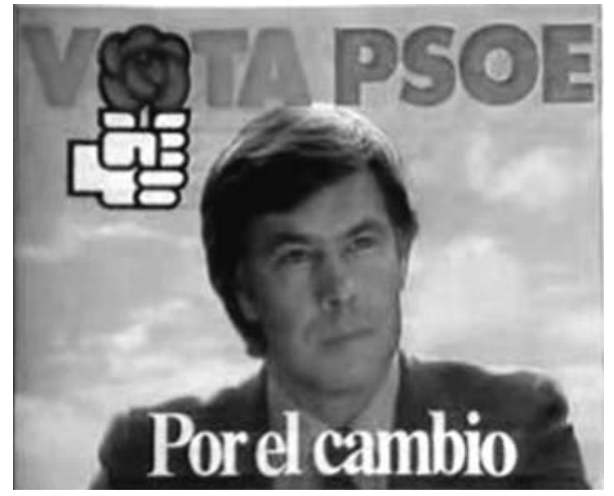
verbo, semánticamente, muy político- a la juventud, sacándola de su tradicional desinterés por la política y de su pasotismo. El mensaje del PSOE poseía el argumento preciso para el contexto en que fue concebido; logró conectar con el cuerpo electoral y resultó inmensamente eficaz, a la vista de los resultados.

El cartel juega con la tipografía, mezclando mayúsculas y minúsculas, y sustituyendo la "o" de "Vota" por la rosa que, junto al puño fue tradicionalmente el símbolo del PSOE.

Meses antes de la celebración de estos comicios, el 23 de febrero de 1981, España había sufrido un intento de golpe de Estado; y pocos meses después, el 27 de agosto de 1982, el entonces Presidente del Gobierno, Leopoldo Calvo Sotelo, en plenas vacaciones parlamentarias, compareció ante la cámaras de televisión y, de acuerdo con las atribuciones que le confería el artículo 115 de la Constitución, anunció la disolución anticipada de las Cortes y la convocatoria de Elecciones generales. En este contexto ganó el "cambio".

En septiembre del año 2010, el término "cambio" ha reaparecido en los eslóganes, como por ejemplo en la precampaña catalana y en diversas formaciones. Es el caso de "El canvi real" que representa al PSC, "El canvi" de CIU, y "Con el cambio más empleo" del PP.

Fuera del ámbito español, en otra convocatoria previa, la palabra "cambio" ha sido clave de la campaña de Barack Obama en las elecciones norteamericanas de 2008: "Change, yes we can" y los dos elementos presentes en el eslogan -el "cambio" y la 
capacidad de cambiar, porque "sí, se puede"- han contagiado a innumerables campañas comerciales y políticas. El cambio que ofrecía Obama era algo más que estrategia de campaña y la clave estaba en convencer y persuadir a los ciudadanos de la necesidad de ese cambio que él representaba prometiendo un futuro mejor, recordando el "he tenido un sueño", presentando una imagen pública serena y haciendo creer que el cambio se haría realidad (LIBERT \& FAULK, 2009:113).

Es el caso, también, de las elecciones primarias que ha celebrado, recientemente, el Partido Socialista de Madrid, y para las que uno de los candidatos, Trinidad Jiménez, eligió como lema "Trini puede".

El ya famoso eslogan "Sí, se puede" no fue utilizado por vez primera por Obama, los antecedentes se encuentran en la campaña panameña de elecciones presidenciales de 2004, cuando el equipo de Martín Torrijos propuso utilizar el lema "Sí se puede", que había sido propuesto por uno de los miembros del equipo de campaña, recordando el grito que los hinchas de la selección panameña utilizaban para dar ánimo a sus jugadores. (SANCHÍs et alii, 2009: 162).

Ciertamente, los lemas positivos, polisémicos, directos y breves funcionan en distintos contextos, aunque en cada uno de ellos adquieran las connotaciones precisas. También sucede esto porque son lemas abiertos, poco concretos, sin rasgos ideológicamente marcados, de tal forma que no comprometen a sus promotores. Las campañas actuales persiguen por encima de todo ganar y no comprometerse. Plantean mensajes que puedan ser fácilmente compartidos por la mayoría.

Las circunstancias históricas del momento o, lo que es lo mismo, la situación y el contexto, determinan la connotación de cada uno de los mensajes. La contextualización es el factor que condiciona la inteligibilidad. Como señala LóPEz EIRE (1998: 16), en referencia al ámbito comercial, un buen mensaje, más allá de la simple adquisición del producto, "consigue integrarse en ese depósito de la conciencia social donde se sedimentan los rastros de la cultura de masas que la publicidad genera y fomenta. Un buen mensaje publicitario influye en la configuración del código de valores sociales por el que se rigen las ideologías y las mitologías de nuestro tiempo".

\section{El eslogan en la campaña de $\mathbf{2 0 0 8}$}

Los partidos en campaña son empresas dedicadas a la captación de votos. Como tales empresas, deben trasmitir con eficacia una imagen de marca. El marketing intenta, en el período electoral, aprovechar las estrategias que pueden resultar adecuadas para situar correctamente al candidato y destacar las diferencias con el adversario, ubicando al partido y al candidato en un espacio propio, donde los mensajes claros, sencillos, concisos, llamativos y emotivos refuercen esa tarea.

La cartelería y las vallas publicitarias siguen haciendo su papel, aunque los espacios y formatos audiovisuales en televisión acaparan la atención de todos.

Podemos señalar como dato comparativo que en 1977 -primeras elecciones democráticas en España-, los partidos políticos invirtieron el 50\% de su presupuesto en carteles y vallas, con los que empapelaron las calles. Hoy siguen utilizando estos formatos para hacerse ver y llamar la atención, siguiendo las reglas publicitarias y ejer- 
ciendo una función de recuerdo y anclaje de toda la campaña, aunque no se correspondan con el $50 \%$ de su presupuesto ${ }^{3}$.

Al margen del presupuesto, la praxis actual aconseja un eslogan sencillo, claro, memorable, breve, sintético y directo: capaz de atraer la atención, como una eficaz llamada publicitaria. El éxito consiste en la capacidad de personalizar dicha llamada.

Los partidos que logran estructurar sus eslóganes de acuerdo con los moldes de la publicidad comercial, son los que tienen más éxito con sus propuestas. De su estrategia creativa va a depender su eficacia persuasiva. Los eslóganes ocupan, además, un lugar privilegiado dentro del spot de campaña, donde ejercen una función de anclaje y de cierre, junto al logo del partido, que representa la imagen de marca. También aparecen en la valla publicitaria, junto a la imagen del candidato.

\subsection{La campaña del PSOE en 2008}

Las principales novedades de la campaña de 2008, en cuanto al eslogan se refiere, se advierten en el desarrollo de la campaña socialista, que presentó una serie de trece eslóganes diferentes, algo que no había sucedido con anterioridad. Hasta esta fecha, los partidos habían presentado un solo eslogan para cada una de sus campañas, que funcionaba como hilo conductor y que, siguiendo las características propias del formato, se centraba en la idea o promesa central del partido para ese momento específico. Los socialistas decidieron, sin embargo, diversificar sus mensajes. Cada cartel presentaba una fotografía diferente, manteniendo siempre como protagonista al candidato, José Luis Rodríguez Zapatero.

Los mensajes políticos se diseñan y deciden cada día más teniendo en cuenta los think tanks. Son expertos, especialistas mediáticos y estrategas quienes, teniendo en cuenta datos y el seguimiento de los sondeos, vertebran los mensajes para grupos concretos de destinatarios. Se trata, siguiendo la tendencia iniciada
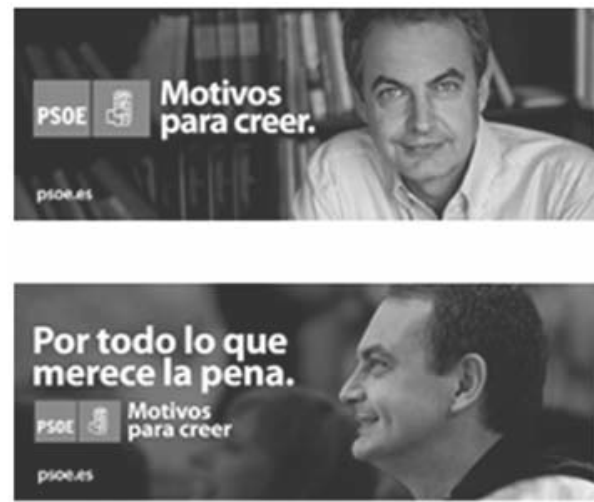
en Estados Unidos hace tres décadas, de comprender los mecanismos cognitivos de la gente y de aplicar los resultados obtenidos en los estudios para diseñar las estrategias comunicativas más eficientes con el objeto de ganar elecciones y mantenerse en el cargo (CASTELLS, 2009: 277).

${ }^{3}$ En la actualidad, las reglas establecidas por el Tribunal de Cuentas del Estado en relación con el gasto electoral, no permiten a las formaciones políticas en campaña destinar más del $25 \%$ del total de su presupuesto a pancartas y carteles, ni más del $20 \%$ en medios de comunicación privados. 


\subsubsection{Trece lemas para una campaña: el caso del PSOE en 2008}

Como hemos apuntado el PSOE presentó, por primera vez, una serie de trece eslóganes. Un lema permanece común a todos los carteles, "Motivos para creer", y, junto a éste, un lema complementario y específico de cada cartela. Cada uno de ellos trataba un tema distinto de los demás, y pretendían claramente segmentar los diferentes públicos. Y así, podía leerse: "Por todo lo que merece la pena"; "Comprometidos con la igualdad"; "Vivimos juntos, decidimos juntos"; "No es lo mismo" (coincidente con el título de una canción de Alejandro Sanz, de moda en ese momento, conocida y compartida por el público más joven); "Porque lo estamos consiguiendo"; "Somos más"; "Soñar con los pies en la tierra"; "Por todo lo logrado"; "Por el pleno empleo"; "Porque no está todo hecho"; "La octava potencia económica, la primera en derechos sociales"; "Ahora que avanzamos, por qué retroceder"; "Podemos llegar tan lejos como queramos" y, por último, el eslogan que utilizaron en el cierre de los spots: "Vota con todas tus fuerzas".

"Motivos para creer" es el hilo conductor, un lema cargado de elementos implícitos, donde la inferencia resulta imprescindible, lo mismo que "Por todo lo que merece la pena". Los lemas de hoy no se cierran semánticamente, no cierran el mensaje con el fin de aglutinar y acoger a todos. Creer ¿en qué exactamente?, "Yes, we can", sí ¿pero qué podemos? Son eslóganes que siguen la línea del cath all party o partido "atrapalotodo", para aglutinar a las mayorías y conseguir el triunfo.

"Comprometidos con la igualdad" denota una pretensión clara de captación del voto femenino. "No es lo mismo" es un lema que no aportaría nada sin constatar su contenido implícito y su inferencia correspondiente. Corresponde al título de una canción de Alejandro Sanz, de moda en aquellos meses, y que ya había sido utilizada por el PSOE en la campaña de las elecciones autonómicas, celebradas meses antes, en junio de 2007. El voto joven reconoció inmediatamente el mensaje. La canción decía "no es lo mismo..., que es distinto", apelando a la diferencia, a la ya dicotomía que plantea el discurso político entre unos y otros. "Somos más" necesita la inferencia correspondiente: el adverbio "más" se utiliza frecuentemente en los eslóganes políticos porque su referencia siempre es positiva, de suma.

Como podemos observar, el adverbio más está presente en diferentes lemas, diferentes convocatorias y en distintos partidos. El lema actual de la Comunidad de Madrid es "La suma de todos", "Vamos a más" fue el eslogan del PP en la convocatoria del año 2000, un eslogan que, prácticamente idéntico, repitieron en el año 2004: "Juntos vamos a más". "Somos más" hace referencia, igualmente, al "caballo ganador", apelando así al voto útil.

"Por el pleno empleo", "Por todo lo logrado", "Porque lo estamos consiguiendo" y "Porque no está todo hecho" explican la necesidad del voto y presentan al electorado los motivos para apoyar a este partido. Dividido en dos bloques - por lo hecho y por lo que falta por hacer-, el destinatario puede ser el votante comprometido, afín y simpatizante. Y así, "Porque no está todo hecho" apela a la necesidad de seguir más tiempo gobernando para continuar la tarea emprendida, apelación recurrente de los partidos en el poder, que siempre piden más tiempo para continuar. 
Dentro de los eslóganes que introducen la causa "por/porque", si bien con un contenido diferente, destaca "Por todo lo que merece la pena", expresión coloquial que se suele utilizar para hablar de lo afectivo, lo más sentimental, las relaciones humanas o nuestra vida privada. La apelación afectiva cobra terreno en los discursos políticos, tanto en el eslogan como en el spot, en claro detrimento de los mensajes de corte ideológico. En esta misma línea se encuentra la invitación a "Soñar con los pies en la tierra".

En todos los lemas mencionados aparece la imagen del candidato, de frente o de perfil, serio o sonriente, en primeros planos o en planos medios, en mangas de camisa o con chaqueta, pero siempre sin corbata, proyectando una imagen cercana y jovial.

En la campaña de 2004, el PSOE había presentado un solo eslogan "Merecemos una España mejor", que apelaba a lo cualitativo, junto con al innovador ZP. Los acrónimos son muy utilizados por los jóvenes y por los programas de televisión (OT, Operación Triunfo, fue uno de los programas que los puso de moda) y son fácilmente divulgados. ZP acabó cuajando de tal forma, que los medios de comunicación empezaron a referirse a Zapatero o al Presidente como ZP y pronto lo hicieron también los ciudadanos. En la campaña de 2008 el candidato protagonizó todos los carteles, sin embargo en ninguno de ellos apareció el acrónimo.

Volviendo a la novedad de presentar varios eslóganes de campaña, trece exactamente, uno por cada día hábil de campaña, ofrecía la ventaja de poder segmentar los públicos destinatarios y especificar los mensajes, si bien la diversificación presentaba algunos inconvenientes, porque no centra la idea o promesa fundamental. El lema principal perdía, de este modo, protagonismo y disminuía la capacidad de recuerdo, al disminuir también la repetición de un mismo mensaje que puede traducirse en una pérdida de eficacia.

\subsection{La campaña del PP en 2008}

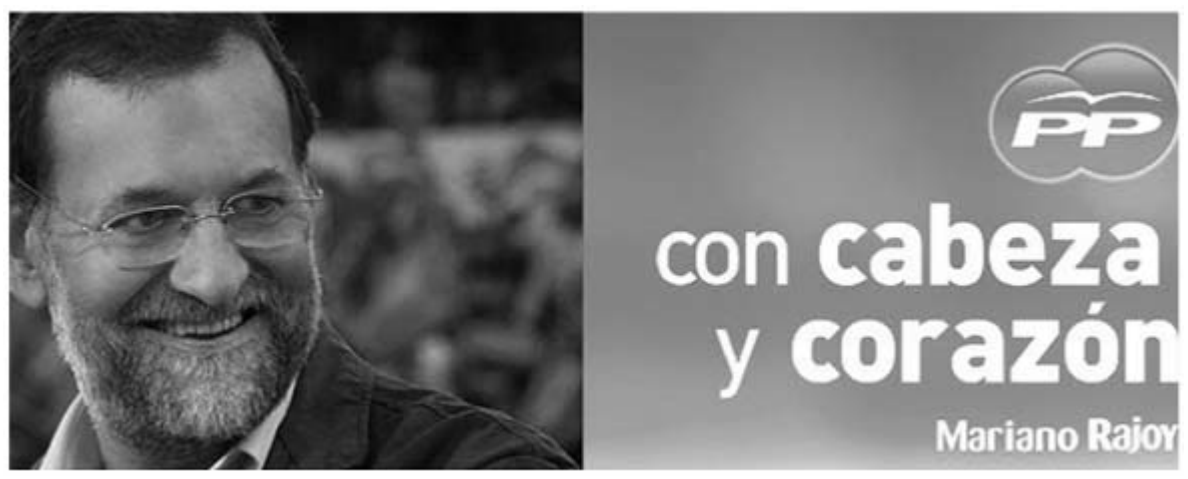

En los carteles y vallas de esta campaña se muestra al candidato popular, sonriente y en escorzo, sin mirar "a cámara". Se trata de una fotografía tomada en el Congreso de Valencia, celebrado el 27 de octubre de 2007, en el que fue proclamado candidato a la Presidencia. Este cartel, explicaba a los medios el director de aquella campaña, Pío 
García-Escudero, resume las principales características del líder del PP, porque "con la 'cabeza' viene desgranando propuestas y con el 'corazón' se ha mostrado preocupado por los problemas de los ciudadanos""4.

El color elegido para la cartela fue el azul propio del partido, y el logotipo usado el de su versión más actual, donde puede verse un solo albatro sobre las siglas de partido, encuadradas en una nube.

En las semanas previas, los populares emplearon también otros eslóganes: "Las ideas claras" y "Con Rajoy, es posible". El primero se siguió utilizando, simultaneándolo con el propio de la campaña: "Con cabeza y corazón". La iniciativa emprendida por el PSOE pudo influir en la idea de simultanear más de un eslogan.

Para este tipo de publicidad, el PP contrató, en la campaña de 2008, 6.000 vallas publicitarias por todo el territorio español, 185 luminosos, 50 monopostes, $1.455 \mathrm{ca}-$ binas, 13.000 banderolas, 1.140 mupis, 8.655 pancartas, 100 coches pequeños de la marca Smart y 800.000 carteles, lo que indica la importancia que las formaciones políticas siguen otorgando a la cartelería, que cumple eficazmente una función de repetición y de recuerdo necesaria para fijar el mensaje, como antes se ha dicho.

Las locuciones tienen mucho en común con los eslóganes políticos, que se construyen a menudo con los rasgos generales de las expresiones fijas: poseen una fosilización en su sintaxis, pero también en su significado. Las locuciones son sintagmas fijos en los que no es posible sustituir de forma libre sus componentes, ni la inclusión de un elemento nuevo, siendo la fijación su principal característica. En marzo de 2008, el eslogan del PP reza "Con cabeza y corazón", utilizando precisamente una locución. Hacer las cosas "con cabeza" no es lo mismo que hacer las cosas "con la cabeza". La primera construcción -"con cabeza"- es, en español, una expresión fija que apela al sentido común, a lo razonable. El lenguaje político utiliza este tipo de expresiones, tan usuales en la lengua común, porque conectan con el lenguaje coloquial de la mayoría, formando parte del lenguaje popular y de la expresión oral cotidiana. Estas características facilitan la conexión con un público amplio y favorecen el recuerdo.

En el aspecto semántico presenta relaciones de antonimia, sinonimia y polisemia. Así, "con cabeza" es antónimo de expresiones como "a tontas y a locas" o "a lo loco".

Nosotros no actuamos "a tontas y a locas" viene a decir el eslogan del PP, sino "con cabeza", al que añade después un toque emotivo o sentimental -"con corazón", de tal forma que no se trata de una cabeza fría, sino de una acertada mezcla de sensatez y sentimiento, que recuerda la novela célebre de Jane Austen (1811), Sense and sensibility. No olvida ese aspecto emotivo cada vez más presente en el discurso electoral dirigido a públicos generales, en esa tendencia hacia el declive de la política ideológica a favor de la política de confianza personal. (DADER, 2008:133).

El ciudadano entiende muy bien estas expresiones, entre otras cosas, porque son las suyas. El significado de este tipo de locuciones viene, en su mayor parte, fijado y establecido, si bien el contexto y las circunstancias del momento aportan el sentido definitivo y el contenido específico que más le concierne, en la situación de la fecha electoral.

4 http://www.eleconomista.es/generales/noticias/368465/02/08/La-campana-electoral-delPartido-Popular-costara-204-millones-de-euros.html 
El PP se presentó a estos comicios, como ha venido siendo habitual, con un solo eslogan.

\subsection{Los otros partidos}

El resto de los partidos, con presupuestos muy inferiores, realizaron campañas más tradicionales, en lo que a cartelería y eslóganes se refiere: un solo eslogan y un solo cartel.

La tabla que sigue da cuenta de los eslóganes que acompañaron y representaron a los partidos que, en orden de mayor a menor representación parlamentaria, concurrieron a las elecciones del año 2008:

\begin{tabular}{|l|l|}
\hline Partido & Eslogan \\
\hline PSOE & Motivos para creer \\
\hline PP & Con cabeza y corazón \\
\hline CIU & Tu voto hará respetar Cataluña \\
\hline PNV & Porque queda mucho por hacer \\
\hline ERC & Objetivo un país de primera \\
\hline IU & Izquierda Unida es + izquierda \\
\hline BNG & Contigo, Galiza decide \\
\hline CC & Habla canario, ponte en tu sitio \\
\hline Na-Bai & Cambia Navarra. Vota Nafarroabai \\
\hline UPyD & UpyD tu voto útil \\
\hline
\end{tabular}

Convergencia i Unió (CIU) presenta un eslogan de corte local, como suele ser habitual en los partidos nacionalistas, y que dirigen su discurso a unos destinatarios muy localizados geográficamente. Lo mismo sucede con Ezquerra Republicana de Cataluña (ERC), Coalición Canaria (CC), Bloque Nacionalista Gallego (BNG) o Nafarroa Bai (Na-Bai). En estos casos es frecuente la apelación a la tierra, a lo local, a lo territorial, a lo más cercano, a "lo nuestro", "al país [nuestro]". "Lo nuestro" es el argumento recurrente y no difiere mucho de los mensajes que presentan en elecciones autonómicas, pues su "blanco" de campaña es el mismo, por mucho que cambie el ámbito elctoral. Llama la atención que el parecido del eslogan del PNV con uno de los presentados por el PSOE. "Porque queda mucho por hacer", dice el PNV, frente al "Porque no está todo hecho", "Porque lo estamos consiguiendo" del PSOE.

Se observa igualmente un parecido in crescendo entre los eslóganes de los distintos partidos, derivado de desideologización de los mensajes, razón por la que todas las formaciones buscan elaborar enunciados persuasivos. Comparten, en suma, técnicas y objetivos, y usan para ello similares estructuras, hasta el punto de comprobar cómo formaciones ideológicamente antagónicas utilizan, en convocatorias subsiguientes, lemas similares si no idénticos.

En el caso de Coalición Canaria (CC), esta formación utiliza el mismo lema de la convocatoria autonómica del año anterior. 
Finalmente, Unión, Progreso y Democracia (UpyD), único partido nuevo en esta convocatoria, apela al voto útil con un eslogan de corte tradicional que incluye, de modo explícito, la palabra "voto": "Tú voto útil", con un estilo nominal y especificando el objetivo.

\section{Conclusiones}

1. La finalidad principal del eslogan político consiste en apelar al votante para fomentar el voto. En los mensajes de propaganda política, la función movilizadora desempeña un papel destacado. Su objetivo fundamental es buscar adhesiones, llamar la atención y provocar simpatías. Se observa, en este sentido, una tendencia, cada vez más creciente, hacia mensajes desideologizados. Se acercan al eslogan de marca comercial y representan la propuesta, el tono de la campaña y la posición relativa con respecto a los adversarios.

2. El eslogan no pretende reflejar la realidad, ni resumir un programa. Las exigencias de condensación y simplificación de sus mensajes se reflejan también en su contenido, que tiende, cada vez más, a eliminar el significado ideológico a favor de contenidos afectivos y poco comprometidos.

3. Si se ha comprobado que con el paso del tiempo los eslóganes están menos cargados de contenido y léxico ideológico, que sí aparecía en las primeras convocatorias y los partidos tienden hoy a frases más genéricas, sin contenido ideológico y que por eso mismo resultan fácilmente intercambiables.

4. En la mayoría de los casos son enunciados cargados de contenido implícito, donde juegan un papel central los elementos culturales, históricos y contextuales, con especial atención a la situación concreta que vive el país en el momento concreto de la campaña. La brevedad y la economía son condición sine qua non en este tipo de discursos.

5. Los enunciados con significados polisémicos y abiertos -como es el caso estudiado de "Por el cambio"- están cada día más presentes, poniendo de manifiesto una clara tendencia al eslogan poco marcado desde el punto de vista ideológico. Se evita así el riesgo de la promesa explícita, singularmente, de cara a una hipotética victoria que conduciría a un gobierno comprometido por sus promesas electorales. Resulta curioso observar como en las últimas elecciones celebradas en nuestro país, las catalanas de noviembre de 2010, sigue apareciendo la palabra cambio.

6. La comprensión del sentido global del eslogan depende, en la mayoría de los casos, de la inferencia oportuna que actualiza los sobrentendidos, del significado implícito, el conocimiento compartido y los elementos contextuales.

7. Las circunstancias históricas del momento o, lo que es lo mismo, la situación y el contexto, determinan la connotación de cada uno de los mensajes. La contextualización es el factor que determina la inteligibilidad.

8. El eslogan político, que cierra habitualmente los spots de campaña, debe ser directo y conciso. Ha de presentar un lenguaje sencillo, con el que hacerse entender, a la primera -just in time-, y por el mayor número de destinatarios.

9. Se descartan en su elaboración las estructuras complejas que puedan distorsionar la comunicación, haciéndola más dificultosa y, consiguientemente, menos eficiente. 


\section{Referencias Bibliografícas}

ARCEO VACAS, José Luis (1993): Campañas electorales y publicidad política en España, 1976-1991. Barcelona, PPU.

BLUMENTHAL, Sidney (1980): The Permanent Campaign. New York, Simon \& Schuster.

CANEL, María José \& SANDERS, Karen (2010): "Para estudiar la comunicación de los gobiernos. Un análisis del estado de la cuestión", en Comunicación y Sociedad, vol. XXIII, n 1 , pp. 19, 31 y 7-48.

CASTELLS, Manuel (2009): Comunicación y poder. Madrid, Alianza Editorial.

DADER, José Luis (2008): "El papel del periodismo actual en la construcción de lo público" en CAPELLÁN, G. (dir.): Opinión pública. Madrid,Trotta, p. 234.

DADER, José Luis (2008): "La adolescente investigación en comunicación política: estructura del campo y tendencias prometedoras”, en MARTÍNEZ NICOLÁS, M. (coord.): Para investigar la comunicación: propuestas teórico-metodológicas. Madrid, Tecnos.

ESCANDELL, María Victoria (2007): Introducción a la pragmática. Barcelona, Ariel Lingüística, p. 31.

FERNÁNDEZ, Julio y GARCIA, Javier (1982): "El futuro es nuestro, de la mayoría que quiere el cambio", en Madrid, El País, 27 de octubre.

GARCÍA BEAUDOUX, Virginia; D'ADAMO, Orlando; y SLAVINSKY, Gabriel (2005): Comunicación política y campañas electorales. Barcelona, Gedisa, pp. 2930.

GARRIDO LORA, Manuel (2000): “El eslogan del año 2000”, en Questiones Publicitarias, $\mathrm{n}^{\circ} 8$, pp. 29-60.

HAAS, Claude Raymond (1965): Teoría, técnica y práctica de la publicidad. Madrid, Rialph.

LIBERT, Barry y FAULK, Rick (2009): Obama, Inc. El éxito de una campaña de marketing. Madrid, Pearson Educación.

LÓPEZ EIRE, Antonio y DE SANTIAGO GUERVÓS, Javier (2000): Retórica y comunicación política. Madrid, Cátedra, pp.12 y 16.

MARTÍN SALGADO, Lourdes (2002): Marketing político. Barcelona, Paidós, pp.80 y 87.

MARTÍNEZ SILVA, Mario y SALCEDO, Alberto (1997): Manual de campaña. México, Consejo Nacional de Ciencias Políticas y Administración Pública, t. I, p. 3.

MAZZOLENI, Gianpietro (2010): La comunicación politica. Madrid, Alianza Editorial.

PEÑA JIMÉNEZ, Palma y GARCÍA JIMÉNEZ, Antonio (2010): “Tipología del spot electoral: una aproximación a partir de la campaña de 2008", en Pensar la Publicidad. Revista Internacional de Investigaciones Publicitarias, vol. IV, $\mathrm{n}^{\circ}$ 2, Madrid- 
Valladolid, Servicio de Publicaciones de la Universidad Complutense de Madrid Servicio de Publicaciones e Intercambio Científico de la Universidad de Valladolid.

PEÑA PÉREZ, Gloria (1999): "El valor persuasivo del eslogan político", en La lengua y los medios de comunicación. Servicio de Publicaciones de la Universidad Complutense de Madrid, pp.143-154.

REBOUL, Oliver (1978): El poder del eslogan. Valencia, Fernando Torres, pp. 42 y 109.

SÁNCHEZ GUZMÁN, José Ramón (1995): Promoción en marketing. Madrid, McGraw-Hill, p. 82.

SANCHÍS, José Luis, MAGAÑA, Marcos y SANMARTÍN, Aleix (2009): Ganar el poder. Madrid, Síntesis.

SARTORI, Giovanni (2007): ¿Qué es la democracia?. Madrid, Taurus Pensamiento.

SWANSON, David L. (1995): "El campo de la comunicación política. La democracia centrada en los medios", en MUÑOZ ALONSO, Alejandro: Comunicación política. Madrid, Universitas.

SWANSON, David L. y MANCINI, Paolo, (1996): Politics, media and modern democracy. An International Study of Innovations en Electoral Campaigning and their consequences. Westport, Connecticut, Praeger.

TUESTA SOLDEVILLA, Fernando (2005): Representación política: las reglas también cuentan: sistemas electorales y partidos políticos. Lima (Perú), Fundación Friedrich Ebert, p. 119.

WILES, Peter (1969): "Un síndrome, no una doctrina: algunas tesis elementales sobre el populismo", en IONESCU, Ghita y GELLER, Ernest (Comp.) (1969) Populismo: sus significados y características. Buenos Aires (Argentina), Amorrortu, pp. 203-204. 